\title{
Comparative study analyzing survival and safety of bevacizumab/carboplatin/paclitaxel and cisplatin/ pemetrexed in chemotherapy-naïve patients with advanced non-squamous bronchogenic carcinoma not harboring EGFR mutation
}

This article was published in the following Dove Press journal:

OncoTargets and Therapy

27 June 2013

Number of times this article has been viewed

\author{
Yasser Abdel Kader ${ }^{1}$ \\ Thierry Le Chevalier ${ }^{2}$ \\ Tamer El-Nahas' \\ Amr Sakr \\ 'Department of Clinical Oncology, \\ Cairo University, Cairo, Egypt; \\ ${ }^{2}$ Department of Medical Oncology, \\ Institut Gustave Roussy, Villejuif, \\ Paris, France
}

Purpose: The majority of Egyptian patients with lung cancer present at a late stage of the disease. Bevacizumab/carboplatin/paclitaxel, as well as cisplatin plus pemetrexed, are both standard regimens for advanced non-squamous bronchogenic cancer. This study compares both regimens, in terms of efficacy and toxicity profile, in Egyptian patients.

Patients and methods: This is a randomized Phase II study comparing toxicity profile and survival in 41 chemotherapy-naïve patients with stage IIIB or IV non-squamous NSCLC, with an ECOG performance status of 0 to 2. The epidermal growth factor receptor (EGFR) mutation detection was performed prior to treatment of all patients. Patients in the first group received: bevacizumab $7.5 \mathrm{mg} / \mathrm{m}^{2}$ on Day 1 and Day 15 ; carboplatin area under the curve- 5 on Day 1; and paclitaxel $60 \mathrm{mg} / \mathrm{m}^{2}$ on Day 1, Day 8, and Day 15 every 4 weeks. In the second group, patients received cisplatin $75 \mathrm{mg} / \mathrm{m}^{2}$ and pemetrexed $500 \mathrm{mg} / \mathrm{m}^{2}$ every 3 weeks.

Results: The combination of bevacizumab/carboplatin/paclitaxel demonstrated higher Grade III-IV toxicity than cisplatin/pemetrexed regarding sensory/motor neuropathy $(P=0.06)$, DVT $(P=0.23)$, proteinuria $(P=0.23)$, and hypertension $(P=0.11)$, as well as Grade II alopecia $(P=0.001)$; however, no significant difference in toxicities between both arms was recorded regarding nausea and vomiting $(P=0.66)$, hematological toxicity, febrile neutropenia $(P=1)$ and fatigue $(P=0.66)$. Progression-free survival was similar for both treatment arms with a median of 6 months $(P=0.978)$. Overall median survival was comparable in both arms, 16.07 months versus 16.01 months $(P=0.89)$.

Conclusion: Bevacizumab/carboplatin/paclitaxel and cisplatin/pemetrexed provided meaningful and comparable efficacy in advanced non-squamous bronchogenic carcinoma not harboring EGFR mutation. No significant difference in toxicity was observed between both treatment arms, apart from bevacizumab/carboplatin/paclitaxel-related risks as DVT, hypertension, proteinuria, sensory/motor neuropathy, and alopecia.

Keywords: bevacizumab, non-small cell lung cancer, NSCLC, pemetrexed

\section{Introduction}

Primary lung cancers are the most common malignancies after nonmelanocytic skin cancer and the leading cause of human cancer deaths worldwide. ${ }^{1}$ Non-small cell lung cancer (NSCLC) accounts for more than $85 \%$ of all lung cancers. ${ }^{2}$ In advanced-stage (stage IIIB or IV) NSCLC, doublet combinations of platinum compounds (cisplatin or carboplatin) with gemcitabine, vinorelbine, or taxanes
Correspondence: Tamer El-Nahas Department of Clinical Oncology, Cairo University, I Al Saray Street, Al Manial, Cairo, Egypt Fax +20 233477771

Email elnahas@sphinxcure.com 
(paclitaxel or docetaxel) are reference regimens ${ }^{3}$ when compared head-to-head in Phase III studies, these doublets have shown comparable efficacy, with variable differences in toxicity profiles. ${ }^{4-8}$

Pemetrexed is a potent inhibitor of thymidylate synthase $e^{9,10}$ and other folate-dependent enzymes, including dihydrofolate reductase and glycinamide ribonucleotide formyltransferase. ${ }^{11}$ Pemetrexed/cisplatin is currently approved in combination for first-line treatment of malignant pleural mesothelioma ${ }^{12}$ and in first-line treatment of nonsquamous advanced NSCLC. ${ }^{13}$

Different studies showed more favorable overall survival (OS) for adenocarcinoma related to low thymidine synthetase expression in non-squamous histology. ${ }^{14,15}$ Besides this, another study in chemotherapy-naïve patients with squamous and adenocarcinoma of the lung demonstrated that baseline expression of the thymidylate synthetase gene and protein were significantly higher in squamous cell carcinoma compared with adenocarcinoma; ${ }^{16}$ however, molecular and other mechanisms that would explain the survival advantage for adenocarcinoma remain unclear. Further molecularmarker studies will help in better stratification of patients to different active regimens.

The addition of bevacizumab, a monoclonal antibody against vascular endothelial growth factor to paclitaxel and carboplatin, led to significant survival benefit. However, this efficacy benefit was seen with an increased risk of treatmentrelated morbidity and deaths. ${ }^{17}$

The recombinant, humanized monoclonal antibody bevacizumab in combination with paclitaxel and carboplatin is approved by the US Food and Drug Administration for first-line treatment of patients with unresectable, locally advanced, recurrent, or metastatic non-squamous NSCLC. ${ }^{17-20}$ Bevacizumab binds to a vascular endothelial growth factor, which is an essential endothelial cell mitogen, a survival factor, and a key factor in tumor-associated angiogenesis.

These two combinations bevacizumab/carboplatin/ paclitaxel and cisplatin/pemetrexed achieved better and almost similar OS in different trials, and are standard regimen for advanced non-squamous NSCLC.

The primary aim of the present study is to analyze a toxicity profile as well as the efficacy of both regimens in term of progression-free survival (PFS), with OS as the secondary endpoint.

\section{Patients and methods}

During the period from September 2008 to May 2010, 65 chemotherapy-naïve patients presented to Dar Al Fouad
Hospital with advanced non-squamous bronchogenic cancer. Sixteen patients were excluded, being epidermal growth factor receptor (EGFR)-mutant. Five patients were excluded because of the presence of brain metastasis. Three others were excluded as well because of an initial presentation with hemoptysis. The remaining 41 patients fulfilled the selection criteria and were assigned to this randomized study.

All patients were eligible if: they had histologically or cytologically confirmed NSCLC, classified as stage IIIB not amenable to curative treatment or stage IV, with at least one unidimensionally measurable lesion, according to the Response Evaluation Criteria in Solid Tumors (RECIST); ${ }^{21}$ an Eastern Cooperative Oncology Group (ECOG) performance status of 0 to $2 ;^{22}$ and were at least 18 years of age. EGFR mutation detection was performed in all non-squamous NSCLC prior to study entry, using an EGFR mutation detection kit (EntroGen Inc, Tarzana, CA, USA). Patients had adequate bone marrow reserve and organ function, including calculated creatinine clearance $\geq 45 \mathrm{~mL} /$ minutes, based on the standard Cockcroft-Gault formula. ${ }^{23}$

Exclusion criteria included: peripheral neuropathy $\geq$ Grade 1, according to the National Cancer Institute Common Toxicity Criteria for Adverse Events version 3.0; progressive brain metastases; or uncontrolled third-space fluid retention before study entry. Patients were also excluded on the basis on: harboring the sensitizing mutation to the EGFR gene; a recent history of bleeding or thrombotic events and ongoing therapeutic anticoagulation; uncontrolled hypertension; unable to interrupt aspirin and other nonsteroidal antiinflammatory drugs; or if they were unable or unwilling to take folic acid, vitamin B12, or corticosteroids.

Non-squamous EGFR wild types fulfilling the selection criteria were randomly allocated into the treatment groups on a ratio of $1: 1$, using a computer system with a closed envelope to one of these two treatment arms:
- Bevacizumab, $7.5 \mathrm{mg} / \mathrm{kg}$
Day 1, Day 15
- Carboplatin, AUC-5
Day 1
- Paclitaxel, $60 \mathrm{mg} / \mathrm{m}^{2}$
Day 1,8 , and 15
$>$ or
- Cisplatin, $75 \mathrm{mg} / \mathrm{m}^{2} \quad$ Day 1
- Pemetrexed, $500 \mathrm{mg} / \mathrm{m}^{2} \quad$ Day 1 .

\section{Baseline and treatment assessments}

Prior to treatment, all patients underwent a medical history and physical examination, and tumor measurements were taken both for palpable lesions as well as lesions assessed by imaging techniques. Positron emission tomography and ultrasound scans were not permitted. The baseline 
assessment method was repeated every other cycle and then every 8 weeks after treatment discontinuation until disease progression. Disease status was assessed in solid tumors according to RECIST. ${ }^{21}$

Twenty patients were assigned to arm 1 (bevacizumab/ carboplatin/paclitaxel), and 21 patients were assigned to arm 2 (cisplatin/pemetrexed). The primary endpoints of the study were PFS and toxicity profile and secondary endpoint was OS.

\section{Statistical analysis}

Comparison of toxicity was done using Fisher's exact test. Survival was estimated using Kaplan-Meier and log rank for comparing curves. $P$-value is always two tailed; and significance was at the 0.05 level.

\section{Results}

In the period from September 2008 to May 2010, a total of 41 patients were randomly assigned (20 patients to bevacizumab/carboplatin/paclitaxel and 21 patients to cisplatin/pemetrexed). The baseline patient and disease characteristics are shown in Table 1.

\section{Efficacy}

In terms of response rate, partial response was witnessed in (12/20 patients) in arm 1 and (10/21 patients) in arm 2, while stable disease was seen in (6/20 patients) in arm 1 and $(9 / 21$ patients $)$ in arm $2(P=0.81)$.

Figure 1 shows the progression-free survival estimate (95\% confidence interval), which was similar for both treatment arms with a median for arm 1 of 6 months (5 to 7 months) versus (vs) 6 months (4 to 8 months) for arm 2 as well $(P=0.978)$.

Overall survival estimate ( $95 \%$ confidence interval) for the patient randomly assigned to (bevacizumab/carboplatin/paclitaxel) was almost similar to that of (cisplatin/pemetrexed), 16.01 (11.47-20.55) months vs 16.07 (14.66-17.49) months $(P=0.89)$.

Figure 2 shows the Kaplan-Meier curve for overall survival. Survival at 12 months and 24 months was $80 \%$ and $20 \%$ for bevacizumab/carboplatin/paclitaxel, respectively, and $85.7 \%$ and $33 \%$ for cisplatin/premetrexed.

In subgroup analysis to which stage IIIB (nine of 41 patients) was compared to stage IV (32 of 41 patients), the overall survival was 13.99 months vs 16.07 months (Figure 3 ),

Table I Baseline characteristics for randomly assigned patients

\begin{tabular}{|c|c|c|c|c|c|}
\hline & \multicolumn{2}{|c|}{$\begin{array}{l}\text { Bevacizumab/ } \\
\text { carboplatin/paclitaxel }\end{array}$} & \multicolumn{2}{|c|}{ Cisplatin/ pemetrexed } & \multirow[t]{2}{*}{$P$-value } \\
\hline & $\%$ & $\begin{array}{l}\text { Number of } \\
\text { patients }\end{array}$ & $\%$ & $\begin{array}{l}\text { Number of } \\
\text { patients }\end{array}$ & \\
\hline Age (years) & & $39-69$ & & $31-67$ & 0.68 \\
\hline Mean & & 53.35 & & 51.62 & \\
\hline$<65$ & $85 \%$ & $(I 7 / 20)$ & $85.7 \%$ & $(|8 / 2|)$ & \\
\hline$\geq 65$ & $15 \%$ & $(3 / 20)$ & $14.3 \%$ & $(3 / 2 I)$ & \\
\hline \multicolumn{6}{|l|}{ Sex } \\
\hline Female & $25 \%$ & $(5 / 20)$ & $28.6 \%$ & $(6 / 2 I)$ & 0.79 \\
\hline Male & $75 \%$ & $(15 / 20)$ & $71.4 \%$ & $(15 / 21)$ & \\
\hline \multicolumn{6}{|l|}{ Smoking status } \\
\hline Never smoker & $15 \%$ & $(3 / 20)$ & $9.5 \%$ & $(2 / 2 I)$ & 0.66 \\
\hline Former/current smoker & $85 \%$ & $(17 / 20)$ & $90.5 \%$ & $(19 / 21)$ & \\
\hline \multicolumn{6}{|l|}{ Stage of disease } \\
\hline IIIB & $25 \%$ & $(5 / 20)$ & $19 \%$ & $(4 / 21)$ & 0.72 \\
\hline IV & $75 \%$ & $(15 / 20)$ & $81 \%$ & $(|7 / 2|)$ & \\
\hline \multicolumn{6}{|c|}{ Most common metastatic sites } \\
\hline Stage IV: whole group & $75 \%$ & $(15 / 20)$ & $80.9 \%$ & $(17 / 21)$ & ND \\
\hline Bone & $86.6 \%$ & $(13 / 15)$ & $88.2 \%$ & $(15 / 17)$ & \\
\hline Liver & $66.6 \%$ & $(10 / 15)$ & $58.8 \%$ & $(10 / 17)$ & \\
\hline Suprarenal & $40 \%$ & $(6 / 15)$ & $41.1 \%$ & $(7 / 17)$ & \\
\hline \multicolumn{6}{|l|}{ ECOG performance status } \\
\hline $0-1$ & $80 \%$ & $(16 / 20)$ & $66.7 \%$ & $(|4 / 2|)$ & 0.34 \\
\hline 2 & $20 \%$ & $(4 / 20)$ & $33.3 \%$ & $(7 / 2 I)$ & \\
\hline \multicolumn{6}{|l|}{ Histologic type } \\
\hline Adenocarcinoma & $75 \%$ & $(15 / 20)$ & $76.2 \%$ & $(16 / 21)$ & 0.79 \\
\hline Adenosquamous & $20 \%$ & $(4 / 20)$ & $14.3 \%$ & $(3 / 2 I)$ & \\
\hline $\mathrm{BAC}$ & $5 \%$ & $(1 / 20)$ & $9.5 \%$ & $(2 / 2 I)$ & \\
\hline
\end{tabular}

Abbreviations: ECOG, Eastern Cooperative Oncology Group; ND, intention not to compare but to describe; BAC, broncho-alveolar carcinoma. 


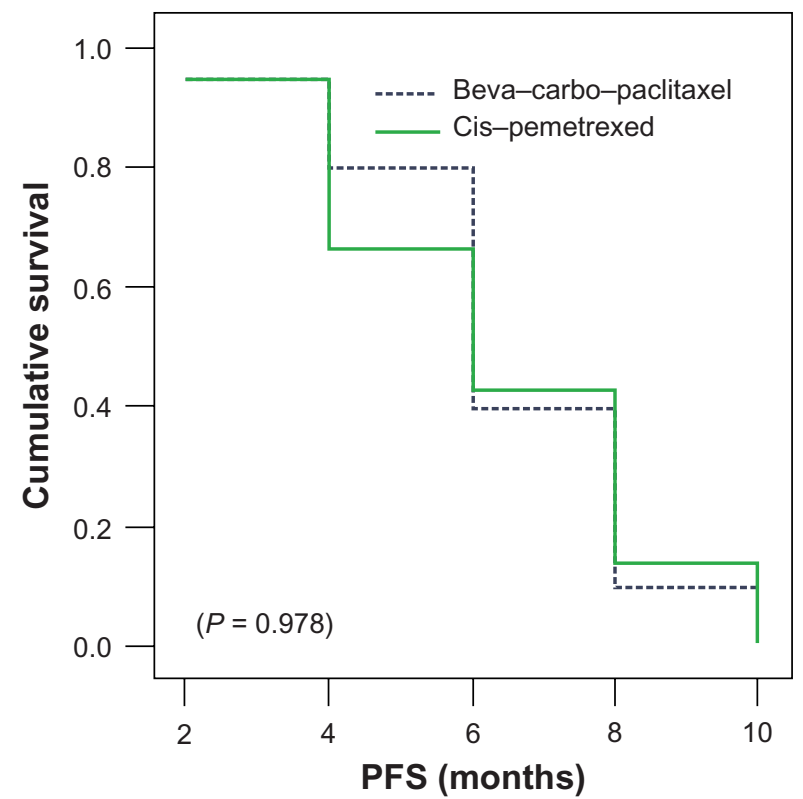

Figure I PFS for both treatment arms.

Abbreviations: Beva-carbo-paclitaxel, bevacizumab/carboplatin/paclitaxel; cis-pemetrexed, cisplatin/pemetrexed; PFS, progression-free survival.

which didn't reach a statistical significance $(P=0.9697)$. However, subgroup analysis to which ECOG 0 to 1 (30 of 41 patients) was compared to EGOG II (eleven of 41 patients) showed that the patient with better performance 0 to 1 (Figure 4 ) tended to achieve better survival at 16.07 months vs 12.05 months $(P=0.4046)$. Finally, subgroup analysis to which positive smoking status (36 of 41 patients) was compared to never-smoker

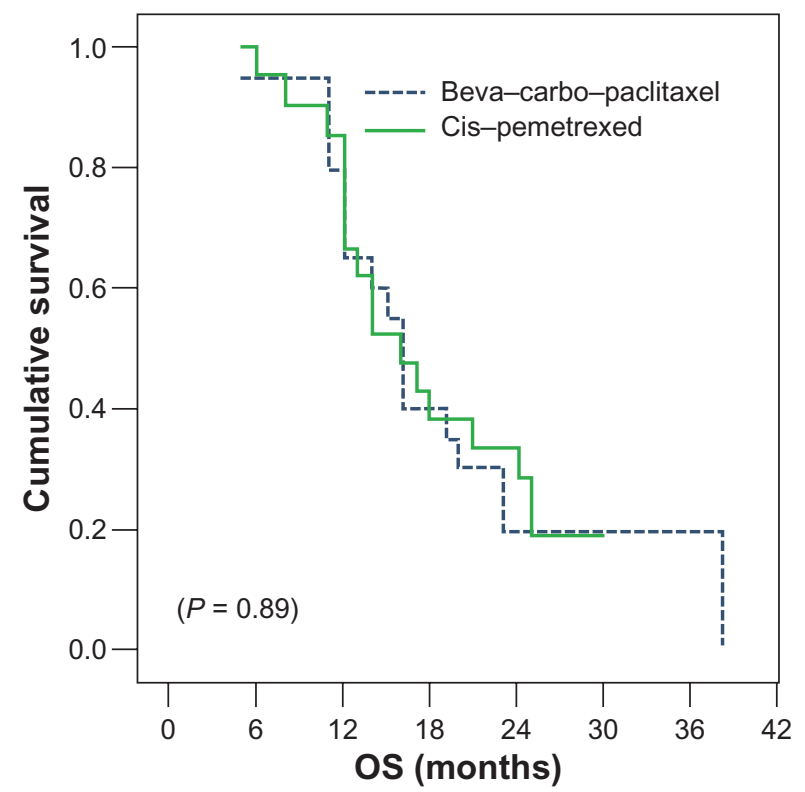

Figure 2 Overall survival for both treatment arms.

Abbreviations: Beva-carbo-paclitaxel, bevacizumab/carboplatin/paclitaxel; cis-pemetrexed, cisplatin/pemetrexed; OS, overall survival.

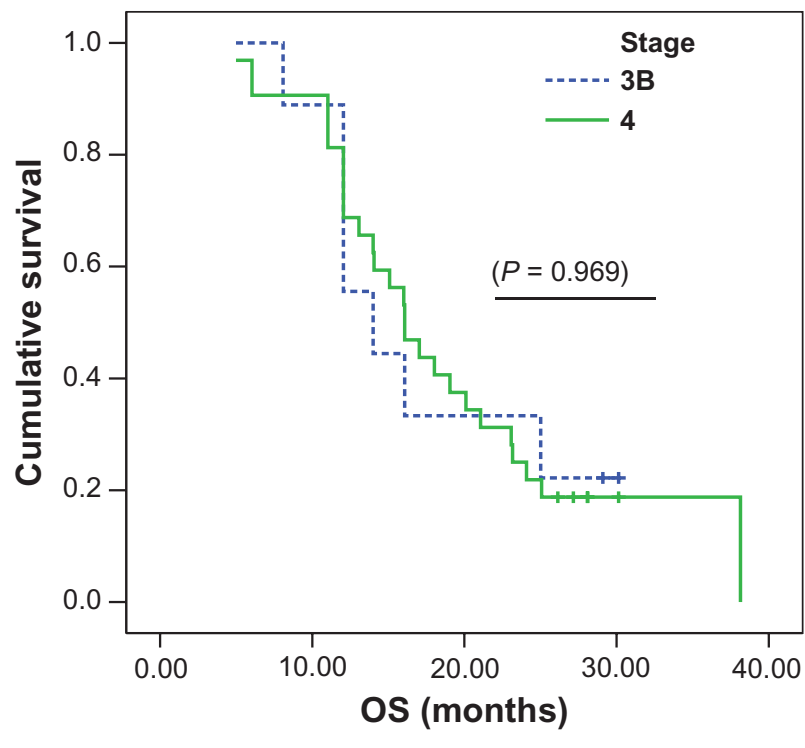

Figure 3 OS according to stage in the whole study population.

Abbreviation: OS, overall survival.

status (five of 41 patients) revealed an overall survival of 16.07 months vs 12.05 months, not reaching statistical significance $(P=0.6571)$.

\section{Safety}

According to the National Cancer Institute Common Toxicity Criteria for Adverse Events version 3.0, the grade III-IV drugrelated toxicity incidents recorded were neutropenia, anemia, and thrombocytopenia. There was no difference between both arms (neutropenia: 3 of 20 patients in arm 1 vs 4 of 21

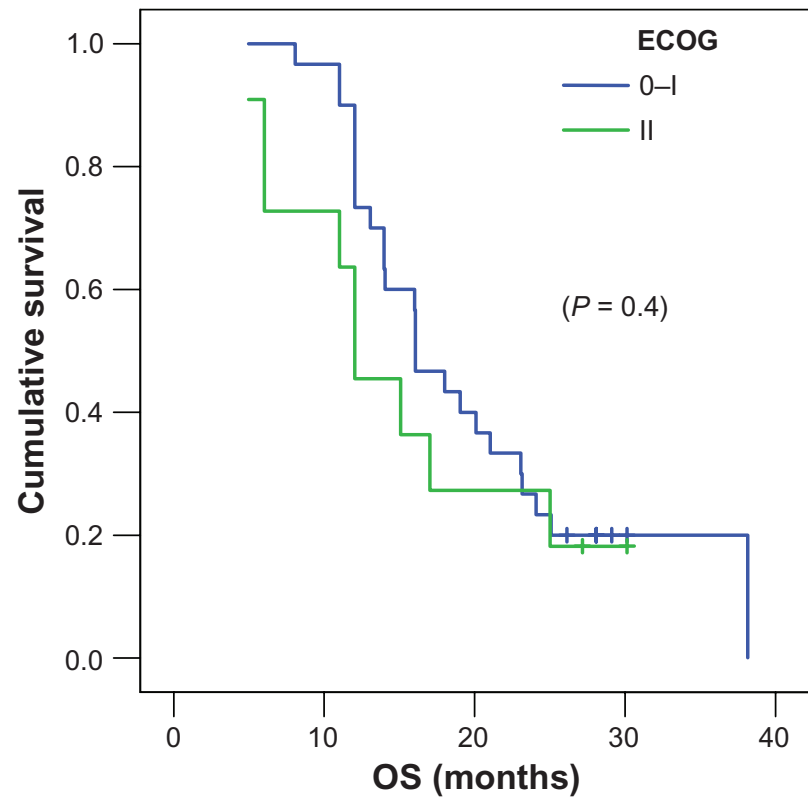

Figure 4 OS by ECOG in the whole study population.

Abbreviations: OS, overall survival, ECOG, Eastern Cooperative Oncology Group. 
patients in arm $2[P=1]$, anemia: 2 of 20 patients in arm 1 vs 3 of 21 patients in arm $2[P=1]$; and thrombocytopenia: 1 in 20 patients in arm 1 vs 4 of 21 patients in arm $2[P=0.43]$ ). Febrile neutropenia requiring hospital admission was noted in 1 in 20 patients in arm 1 and 2 in 21 patients in arm 2 $(P=1)$. Nausea and vomiting was in 2 of 20 patients in arm 1 and higher in arm 2 (4 in 21 patients) $(P=0.66)$. Fatigue was noted in 3 in 20 patients in arm 1 and 2 in 21 patients in arm $2(P=0.66)$.

Hypertension was also higher in arm 1 ( 3 of 20 patients) vs no hypertension recorded in arm $2(P=0.11)$. Proteinuria also was recorded in arm 1 (2 of 20 patients) and was not recorded in arm $2(P=0.23)$. Deep venous thrombosis (DVT) was higher in the bevacizumab-containing arm (4 in 20 patients) but not significantly different compared to arm 2 ( 2 of 21 patients) $(P=0.41)$. Sensory/motor neuropathy was more evident in arm 1 ( 8 of 20 patients) vs arm 2 (3 of 21 patients), although not reaching significance $(P=0.06)$. Alopecia (Grade II alopecia) was significantly higher in arm 1 (18 of 20 patients) vs arm 2 ( 1 of 21 patients) $(P=0.001)$. The toxicity profile difference between both arms is demonstrated in Table 2.

\section{Discussion}

It has been reported that the addition of bevacizumab to carboplatin/paclitaxel in previously untreated patients with advanced non-squamous NSCLC was associated with improved OS. ${ }^{17}$ On the other hand, the combination of cisplatin/pemetrexed improved OS, when compared to the doublet combination of platinum compound with

Table 2 Randomly assigned treated patients common toxicity criteria (Worst Grade 3-Grade 4)

\begin{tabular}{|c|c|c|c|}
\hline $\begin{array}{l}\text { Toxicity G3-4 } \\
\text { (CTCAE) }\end{array}$ & $\begin{array}{l}\text { Bevacizumab/ } \\
\text { carboplatin/ } \\
\text { paclitaxel }\end{array}$ & $\begin{array}{l}\text { Cisplatin/ } \\
\text { pemetrexed }\end{array}$ & $P$-value \\
\hline \multicolumn{4}{|l|}{ Hematologic } \\
\hline Neutropenia & (3/20 patients) & (4/2I patients) & 1.0 \\
\hline Anemia & (2/20 patients) & (3/2I patients) & 1.0 \\
\hline Thrombocytopenia & (I/20 patients) & (4/2I patients) & 0.43 \\
\hline Febrile neutropenia & (I/20 patients) & ( $2 / 21$ patients) & 1.0 \\
\hline Nausea and vomiting & (2/20 patients) & (4/2I patients) & 0.66 \\
\hline Fatigue & (3/20 patients) & (2/2I patients) & 0.66 \\
\hline Alopecia grade 2 & (I8/20 patients) & (I/2I patients) & 0.001 \\
\hline Hypertension & (3/20 patients) & (0/2I patients) & 0.11 \\
\hline Proteinuria & (2/20 patients) & (0/2I patients) & 0.23 \\
\hline DVT & (4/20 patients) & (2/2I patients) & 0.41 \\
\hline $\begin{array}{l}\text { Sensory/motor } \\
\text { neuropathy }\end{array}$ & (8/20 patients) & (3/2I patients) & 0.06 \\
\hline
\end{tabular}

Abbreviations: CTCAE, Common Terminology Criteria for Adverse Events version 3.0; DVT, deep venous thrombosis. gemcitabine. ${ }^{13}$ Both of these two combinations achieved better and almost similar OS in different trials, and are standard regimen for advanced non-squamous NSCLC. However, direct comparison of efficacy across different randomized clinical studies could lead to some biased conclusions due to different patient populations.

The issue of bevacizumab dosing in advanced nonsquamous NSCLC, whether $7.5 \mathrm{mg} / \mathrm{kg}$ or $15 \mathrm{mg} / \mathrm{kg}$, remains discussable and depends on the chemotherapy backbone. In the AVAstin in Lung (AVAiL) study, ${ }^{24} 15 \mathrm{mg} / \mathrm{kg}$ every 3 weeks with paclitaxel/carboplatin in (ECOG 4599) and $7.5 \mathrm{mg} / \mathrm{kg}$ every 3 weeks with gemcitabine/cisplatin were studied; yet, in our study, we assumed that $7.5 \mathrm{mg} / \mathrm{kg}$ every 2 weeks would be a compromise between toxicity and efficacy, which is probably why we didn't record any life-threatening hemorrhagic side effects or treatment-related mortality.

This study compared both regimens in terms of toxicity and efficacy (response rates, PFS, and OS rates) in a small sample of the Egyptian population. A partial response was observed in $60 \%$ in arm 1 and $47.6 \%$ in arm 2 , while stable disease was seen in $30 \%$ in arm 1 and $42 \%$ in arm 2 . This response rate was meaningful and denoted the comparable activity of both regimens in non-squamous EGFR nonmutant bronchogenic cancer.

The median time to progression in both arms was 6 months, which was also comparable to that achieved in ECOG of 6.2 months and that of the study conducted by Scagliotti et al of 5.3 months. ${ }^{13}$

The combination of bevacizumab/carboplatin/paclitaxel demonstrated higher Grade 3-4 toxicity than cisplatin/ pemetrexed, in terms of the well-known bevacizumab/ carboplatin/paclitaxel-related hazards, such as sensory/motor neuropathy, DVT, proteinuria, and hypertension, as well as alopecia Grade 2. However, no significant difference in toxicity was observed regarding nausea and vomiting, hematological toxicity, and febrile neutropenia between both arms.

The median survival for both arms was equivalent at 16.07 months and 16.01 months; this is longer than both the median previously reported in ECOG $45999^{17}$ of 12.3 months and the 12.6 months reported in the study conducted by Scagliotti et al. ${ }^{13}$ Despite the small size of our study, this better overall survival can be attributed to eventual populationrelated biological factors. The achieved median survival in both arms reflects the positive effect of both regimens on survival.

Surprisingly, stage IV patients (32 of 41 patients) and smokers ( 36 of 41 patients) tended to have a better OS than stage IIIB patients (9 of 41 patients) and nonsmokers (5 of 
41 patients), which might be attributed to the smaller number of stage IIIB patients and nonsmokers in comparison to Stage IV patients and smokers.

In conclusion, cisplatin/pemetrexed and bevacizumab/ carboplatin/paclitaxel provided meaningful and comparable efficacy in advanced non-squamous EGFR nonmutant bronchogenic carcinoma. There was no significant difference in toxicities, apart from in DVT, hypertension, sensory/ motor neuropathy, proteinuria, and alopecia, which were more common in the bevacizumab-containing regimen. Their efficacy may allow these to become the preferred regimens, although with special attention to bevacizumab-related risks in certain patients.

These results warrant future prospective studies, specifically designed to evaluate biological markers which may guide the selection of patients most likely to benefit from either of these two regimens.

\section{Acknowledgments}

The authors would like to acknowledge the oncology team registrars and nurses at Dar Al Fouad Hospital, who made it possible to conduct this clinical trial. Last, but not least, we acknowledge support from Nelly Ali Eldin of the National Cancer Institute Egypt for her volunteer contribution for statistical analysis.

\section{Disclosure}

The authors report no conflicts of interest in this work.

\section{References}

1. Karim-Kos HE, de Vries E, Soerjomataram I, Lemmens V, Siesling S, Coebergh JW. Recent trends of cancer in Europe: a combined approach of incidence, survival, and mortality for 17 cancer sites since the 1990s. Eur J Cancer. 2008;44(10):1345-1389.

2. Govindan R, Page N, Morgensztern D, et al. Changing epidemiology of small-cell lung cancer in the United States over the last 30 years: analysis of the surveillance, epidemiologic, and end results database. J Clin Oncol. 2006;24(28):4539-4544.

3. Pfister DG, Johnson DH, Azzoli CG, et al. American Society of Clinical Oncology treatment of unresectable non-small-cell lung cancer guideline: update 2003. J Clin Oncol. 2004;22(2):330-353.

4. Schiller JH, Harrington D, Belani CP, et al. Comparison of four chemotherapy regimens for advanced non-small-cell lung cancer. $N$ Engl J Med. 2002;346(2):92-98.

5. Scagliotti GV, De Marinis F, Rinaldi M, et al. Phase III randomized trial comparing three platinum-based doublets in advanced non-small-cell lung cancer. J Clin Oncol. 2002;20(21):4285-4291.

6. Kelly K, Crowley J, Bunn PA Jr, et al. Randomized phase III trial of paclitaxel plus carboplatin versus vinorelbine plus cisplatin in the treatment of patients with advanced non-small-cell lung cancer: a Southwest Oncology Group trial. J Clin Oncol. 2001;19(13):3210-3218.

7. Fossella F, Pereira JR, von Pawel J, et al. Randomized, multinational, phase III study of docetaxel plus platinum combinations versus vinorelbine plus cisplatin for advanced non-small-cell lung cancer: the TAX 326 study group. J Clin Oncol. 2003;21(16):3016-3024.
8. Le Chevalier T, Scagliotti G, Natale R, et al. Efficacy of gemcitabine plus platinum chemotherapy compared with other platinum containing regimens in advanced non-small-cell lung cancer: a meta-analysis of survival outcomes. Lung Cancer. 2005;47(1):69-80.

9. Taylor EC, Kuhnt D, Shih C, et al. A dideazatetrahydrofolate analogue lacking a chiral center at C-6, N-[4-[2-(2-amino-3,4-dihydro-4-oxo7H-pyrrolo[2,3-d]pyrimidin-5-yl)ethyl]benzoyl]-L-glutamic acid, is an inhibitor of thymidylate synthase. J Med Chem. 1992;35(23): 4450-4454.

10. Schultz RM, Patel VF, Worzalla JF, Shih C. Role of thymidylate synthase in the antitumor activity of the multitargeted antifolate, LY231514. Anticancer Res. 1999;19(1A):437-443.

11. Shih C, Habeck LL, Mendelsohn LG, Chen VJ, Schultz RM. Multiple folate enzyme inhibition: mechanism of a novel pyrrolopyrimidine-based antifolate LY231514 (MTA). Adv Enzyme Regul. 1998;38:135-152.

12. Vogelzang NJ, Rusthoven JJ, Symanowski J, et al. Phase III study of pemetrexed in combination with cisplatin versus cisplatin alone in patients with malignant pleural mesothelioma. J Clin Oncol. 2003;21(14):2636-2644.

13. Scagliotti GV, Parikh P, von Pawel J, et al. Phase III study comparing cisplatin plus gemcitabine with cisplatin plus pemetrexed in chemotherapy-naive patients with advanced-stage non-small-cell lung cancer. J Clin Oncol. 2008;26(21):3543-3551.

14. Sigmond J, Backus HH, Wouters D, Temmink OH, Jansen G, Peters GJ. Induction of resistance to the multitargeted antifolate Pemetrexed (ALIMTA) in WiDr human colon cancer cells is associated with thymidylate synthase overexpression. Biochem Pharmacol. 2003;66(3): 431-438.

15. Giovannetti E, Mey V, Nannizzi S, et al. Cellular and pharmacogenetics foundation of synergistic interaction of pemetrexed and gemcitabine in human non-small-cell lung cancer cells. Mol Pharmacol. 2005;68(1): $110-118$.

16. Ceppi P, Volante M, Saviozzi S, et al. Squamous cell carcinoma of the lung compared with other histotypes shows higher messenger RNA and protein levels for thymidylate synthase. Cancer. 2006;107(7): 1589-1596.

17. Sandler A, Gray R, Perry MC, et al. Paclitaxel-carboplatin alone or with bevacizumab for non-small-cell lung cancer. $N$ Engl $J$ Med. 2006;355(24):2542-2550.

18. Avastin $^{\circledR}$ (bevacizumab) [package insert]. South San Francisco, CA, USA: Genentech Inc; 2007.

19. Johnson DH, Fehrenbacher L, Novotny WF, et al. Randomized phase II trial comparing bevacizumab plus carboplatin and paclitaxel with carboplatin and paclitaxel alone in previously untreated locally advanced or metastatic non-small-cell lung cancer. J Clin Oncol. 2004;22(11):2184-2191.

20. Sandler A. Bevacizumab in non-small cell lung cancer. Clin Cancer Res. 2007;13(15 Pt 2):s4613-s4616.

21. Therasse P, Arbuck SG, Eisenhauer EA, et al. New guidelines to evaluate the response to treatment in solid tumors. European Organization for Research and Treatment of Cancer, National Cancer Institute of the United States, National Cancer Institute of Canada. J Natl Cancer Inst. 2000;92(3):205-216.

22. Oken MM, Creech RH, Tormey DC, et al. Toxicology and response criteria of the Eastern Cooperative Oncology Group. Am J Clin Oncol. 1982;5(6):649-655.

23. Cockcroft DW, Gault MH. Prediction of creatinine clearance from serum creatinine. Nephron. 1976;16(1):31-41.

24. Reck M, von Pawel J, Zatloukal P, et al. Phase III trial of cisplatin plus gemcitabine with either placebo or bevacizumab as first-line therapy for nonsquamous non-small-cell lung cancer: AVAiL. J Clin Oncol. 2009;27:1227-1234. 
OncoTargets and Therapy

\section{Publish your work in this journal}

OncoTargets and Therapy is an international, peer-reviewed, open access journal focusing on the pathological basis of all cancers, potential targets for therapy and treatment protocols employed to improve the management of cancer patients. The journal also focuses on the impact of management programs and new therapeutic agents and protocols on

patient perspectives such as quality of life, adherence and satisfaction. The manuscript management system is completely online and includes a very quick and fair peer-review system, which is all easy to use. Visit http://www.dovepress.com/testimonials.php to read real quotes from published authors.

Submit your manuscript here: http://www.dovepress.com/oncotargets-and-therapy-journal 